\title{
Discurso e (des)igualdade social
}

\section{Karine Correia dos Santos de Oliveira* PUC MG}

A obra Discurso e (des)igualdade social, organizada por Lara e Limberti, foi publicada em 2015, pela editora Contexto. Nela, o leitor encontrará um trabalho de exposição de parte da trajetória e dos resultados de investigações de pesquisadores vinculados a universidades de diferentes nacionalidades (brasileiras, americanas, europeias, dentre outras). Os artigos são dedicados ao estudo dos discursos de e sobre os excluídos da sociedade, a partir de textos com diferentes temas: adolescentes sem moradia, candidatura a presidência, machismo, feminismo etc. Os artigos, cada um com sua especificidade, podem contribuir com a formação de interessados em debates e pistas linguísticas e discursivas indicadoras de formas de exclusão social, preconceitos, autoritarismos e formas de violência. Além disso, podem alimentar estudos sobre a formação e a atuação em ciências sociais e humanas aplicadas, incluindo opções teóricas e analíticas. O livro é composto por uma breve apresentação assinada pelas organizadoras, onze artigos e uma sessão com informações acadêmicas e profissionais das organizadoras e dos autores. Esta resenha propõe uma ênfase aos principais objetivos e resultados de cada trabalho, iluminando alguns caminhos metodológicos, passagens consideradas mais significativas, buscando alguns diálogos com leituras de outros autores.

No primeiro capítulo, traduzido por Clebson Luiz de Brito e Wander Emediato de Souza, "Identidade linguística, identidade cultural: uma relação paradoxal”, Charaudeau defende a dificuldade de separar a instância individual da social. Admite a existência de identidades individuais e coletivas. A construção da individualidade pode ser entendida a partir dos seguintes dizeres:

Para que haja tomada de consciência identitária, é necessário que se perceba uma diferença e que se estabeleça uma certa relação face ao outro. (p. 18).

A relação com o outro, esclarece o autor, é orientada tanto por movimentos de atração como de rejeição. Para Benveniste (2005, p. 255),

O que diferencia “eu” de "tu” é, em primeiro lugar, o fato de ser, no caso de "eu”, interior ao enunciado e exterior a "tu”, mas exterior de maneira que não suprime a realidade humana do diálogo.

Essa dupla força também provoca efeitos na construção identitária dos grupos, que também são orientados pela língua nacional. A discussão que o autor faz sobre a língua é dentro do contexto cultural e discursivo, podendo ser melhor entendida com a leitura e reflexão sobre o trecho a seguir:

\footnotetext{
* Doutoranda em Linguística no Programa de Pós-Graduação stricto sensu em Letras da Pontifícia Universidade Católica de Minas Gerais (PUC Minas). Bolsista da Coordenação de Aperfeiçoamento de Pessoal de Nível Superior (CAPES), sob orientação da Professora Doutora Juliana Alves Assis. karineletras@yahoo. com.br
} 
Não são tanto as palavras na sua morfologia nem as regras de sintaxe que são portadoras de cultura, mas, sim, as maneiras de falar de cada comunidade, as maneiras de empregar as palavras, os modos de raciocinar, de relatar, de argumentar para fazer rir, para explicar, para persuadir, para seduzir. (p. 27).

Em outras palavras, “o novo não está no que é dito, mas no acontecimento de sua volta.” (FOUCALT, 2007, p. 26). Charaudeau finaliza com uma proposta de definição para "identidade cultural”.

No segundo artigo, "Discurso das elites e racismo institucional”, traduzido por Glaucia Proença Lara e Regina Célia Vieira, van Dijk escolhe examinar o papel das elites e das instituições na produção e reprodução do racismo. O autor esclarece que racismo, para ele, é “essencialmente um sistema de dominação e desigualdade social.” (p. 33). Também diferencia a reação aos imigrantes por elites e por populares, na Europa; compara formas antigas e contemporâneas de racismo, ilustrando com passagens de textos escritos e falados do domínio da política, da imprensa e de manuais escolares.

Possenti, no terceiro capítulo, "Durações históricas e sua relação com público e privado”, analisa diversos textos humorísticos que provam a existência de diferentes temporalidades, dependendo do gênero textual, da temática e do discurso. A temporalidade a que o autor se refere é discursiva e histórica, o que não significa que não possa ser um pouco capturada por formas temporais (“este”, “aqui”, “agora”, “amanhã” etc.), estudadas por Benveniste (2005), partindo de um olhar menos amplo para os fatos. Língua e discurso estão entrelaçados, assim como ensina Barthes (2007, p. 30), “a língua aflui no discurso, o discurso reflui na língua, eles persistem um sob o outro, como na brincadeira de mão.”. Nessa perspectiva, apesar de não ser possível determinar o surgimento de um discurso, sabe-se que o poder está nas instituições que o orientam. (FOUCAULT, 2007).

Barros, autora do quarto artigo, "Intolerância, preconceito e exclusão” opta por explicar a organização narrativa e discursiva dos discursos intolerantes, associados ao discurso da punição com efeitos cognitivos e pragmáticos. As palavras da autora podem ser mais esclarecedoras

O discurso intolerante considera o diferente aquele que rompe pactos e acordos sociais, por não ser humano, por ser contrário à natureza, por ser doente e sem ética ou estética, e que, por isso mesmo, é temido, odiado, sancionado negativamente e punido. (p. 65).

A questão linguística não fica de fora dessa discussão, sobre a qual a autora menciona diversas contradições ligadas a aspectos históricos e de formação da identidade da língua portuguesa.

Na sequência, no artigo quinto, “A política da desigualdade no Brasil: adolescentes em situação de rua”, Garcia denuncia a irresponsabilidade dos 
poderes com a realidade de adolescentes moradores das ruas da capital do Brasil. Realidade que é, em parte, relacionada às mudanças históricas na constituição familiar. A desigualdade econômica e a exclusão são entendidas como coisas distintas em

Enquanto o termo desigualdade econômica implica a distribuição diferenciada entre seus participantes do que é produzido dentro de uma sociedade, a exclusão significa pôr fora, expulsar indivíduos ou grupos sociais de um espaço de igualdade social. (p. 85).

Os dados analisados partiram de diferentes notícias sobre a temática.

Maingueneau contou com a tradução de Glaucia Proença Lara e Aline Saddi Chaves, no capítulo seis, "O poeta e o camponês: o impossível ponto de vista do dominado”, por meio do qual o autor examina poemas antigos, em que o dominador e o dominado são respectivamente o burguês e o artista. A estrutura linguística e discursiva dos poemas dizem sobre e pelo povo, o homem do campo. Essa identificação da produção artística com a vida do camponês possibilita que a voz do dominado seja ouvida e também lida nos poemas. Concepção de produção artística literária que dialoga com Barthes (2007, p. 18) em “a literatura faz girar os saberes, não fixa, não fetichiza nenhum deles; ela lhes dá um lugar indireto, e esse indireto é precioso.” A possibilidade de olhar o povo por meio de outro está ligada a esse funcionamento indireto da produção literária. Sem esquecer que

O autor é aquele que dá à inquietante linguagem da ficção suas unidades, seus nós de coerência, sua inserção no real. (FOUCAULT, 2007, p. 28).

Ducard trabalha com transcrições de participações em um programa de rádio francesa, voltado para dar voz a diferentes excluídos por tensões sociais quanto a questões religiosas, econômicas, políticas de imigração, de nacionalidades, de profissão, de gênero etc. Isso, no sétimo capítulo, “Dar a palavra: da reportagem radiofônica à ficção documental”, traduzido por Glaucia Proença Lara e Aline Saddi Chaves. As transcrições foram feitas sem eliminar todas as marcas da subjetividade, dialogando com o posicionamento de Marcuschi (2005), ao defender que não existe alguma característica ou algum traço linguístico na fala ou na escrita (uma forma linguística) que possa marcar com absoluta segurança a delimitação entre ambas as modalidades. (MARCUSCHI, 2005, p. 18). Além disso,

A formalidade ou a informalidade na escrita e na oralidade não são aleatórias, mas se adaptam às situações sociais. Não se trata de um espelhamento, pois a língua não reflete a realidade, e sim ajuda a constituí-la como atividade.

No capítulo seguinte, "Narrativa de vida e construção da identidade”, Machado toma como objeto de análise duas narrativas francesas: a de 
um poeta que viveu no século XV e a sobre um morador das ruas de Paris, publicada em uma reportagem de um jornal francês contemporâneo, que é traduzido para o português e vendido no Brasil. Nas análises, a ironia e o discurso relatado são verificados como estratégias de demonstração de vários sentimentos dos marginalizados. Além disso, a professora lembra que

A igualdade entre os humanos é algo instável e relativo; já a desigualdade, sim, ela existe, e isso desde que o mundo é mundo. (p. 136).

Estas são linhas inquietantes e desafiadoras para aqueles interessados nas dificuldades daqueles que desconhecem o poder da sua voz, seja por meio da oralidade ou da escrita.

No nono artigo, “A afetividade no discurso populista”, traduzido por Ricardo Gualda, Bolívar apresenta sua pesquisa a respeito de discursos produzidos para a campanha presidencial Venezuelana, em 2012. As análises são centradas na especificidade do discurso político populista, que teve mais espaço no domínio da oralidade. A afetividade é uma estratégia discursiva verificada nos dados e, além disso, de diferentes tipos. A interação e as funções de cada manifestação afetiva também são muito importantes nas reflexões.

No décimo texto, “Mulheres e emoções em cena”, Lima analisa as emoções em dois filmes de um mesmo diretor brasileiro. O estudo é pautado no incômodo de que

vivemos em um país em que o lugar de inferioridade conferido às mulheres se verifica em diversos segmentos da sociedade: a naturalização da diferença se estabelece desde postos de trabalho menos remunerados à violência simbólica e física. (p. 164).

Apesar desse pressuposto terrível, a autora avalia os filmes como inovadores por apresentarem representações de mulheres que, mesmo diante de problemas diversos, movimentam-se, viajam, persistem com suas tentativas de "invenção", capacidade de simbolizar, o que distingue homens dos outros animais. (BENVENISTE, 2005, p. 29). Como se (re)inventar sem conhecer diferentes mundos e olhares, senão por meio dos leituras e livros? A falta de livrarias e bibliotecas públicas, em várias regiões de Belo Horizonte é uma realidade que ainda reflete a desigualdade de acesso ao ambiente de estudo e aos livros para muitos. Uma discussão ligada à democratização do ensino no país. Um tema muito caro a aos problemas que envolvem a exclusão social no país. (MATENCIO, 1994).

Por fim, com o artigo "Sentidos para a homossexualidade”, Borges e Coutinho expõem um estudo sobre diferentes formas de entendimento da homossexualidade, a partir de entrevistas semidirigidas ou mais próximas de conversas cotidianas. Os dados possibilitaram a verificação de quatro categorias. 1) descobrir-se gay; 2) assumir a homossexualidade; 3) ser homossexual; 4) a igualdade na diferença. 
O livro Discurso e (des)igualdade social é uma publicação com inúmeras possibilidades de reflexões sobre discursos de marginalizados, apresentando textos emocionantes com dizeres silenciados, nos meios de circulação prestigiada, mas reconhecidos, na publicação, como parte da identidade cultural de um país também configurado por aqueles sensíveis aos problemas que a desigualdade social provoca na vida das famílias, dos grupos sociais e, principalmente, daquelas pessoas que sofreram ou sofrem algum tipo de exclusão social.

\section{Referências}

BARTHES, Roland. Aula. 13a . ed. São Paulo: Cultrix, 2007.

BENVENISTE, Émile. Problemas de lingüística geral I. 5ª ed. Campinas (SP): Pontes Editores, 2005.

FOUCAULT, Michel. A ordem do discurso. São Paulo, Edições Loyola, 2007.

LARA, Glaucia Proença; LIMBERTI, Rita Pacheco (Org.) Discurso e (des)igualdade social. São Paulo: Contexto, 2015, 206p.

MARCUSCHI, LuizAntônio; XAVIER, Antonio Carlos (Org.). Hipertexto e gêneros digitais: novas formas de construção de sentido. 2. ed. Rio de Janeiro: Lucerna, 2005.

MATÊNCIO, Maria de Lourdes Meirelles. Leitura, produção de textos e a escola: reflexões sobre o processo de letramento. São Paulo: Mercado de Letras, 1994. 